\title{
Nuclear Magnetic Resonance (NMR) Analysis of D - (+) - Glucose: A Guide to Spectrometric Structural Elucidation of Sugars
}

\author{
E. U. Onche ${ }^{1}$, B.W. Tukura ${ }^{2} *$, S. S. Bako ${ }^{2}$ \\ ${ }^{I}$ Department of Chemistry, College of Education, P.M.B 05, Akwanga, Nasarawa State, Nigeria \\ ${ }^{2}$ Department of Chemistry, Faculty of Natural and Applied Sciences, Nasarawa State University, Keffi, Nigeria
}

Abstract: NMR spectroscopy has a wide range of applications including exchange phenomena, the identification and structural studies of complex biomolecules. $1 D{ }^{I} H$-NMR without water suppression, $1 D$ Carbon, $1 D^{13} C$-DEPT135, 2D Cosy, $2 D$ HSQC, $2 D$ TOCSY, $2 D H M Q C$, and $2 D H M B C$ techniques were used to completely elucidate the structure of glucose with spectral induced at $400 \mathrm{MHz}$. The spectral were analysed using spinworks 3. The results obtained from the spectral data were systematically combined to elucidate the structure of the D-glucose. Full characterisation of D-glucose was achieved by assigning ${ }^{1} \mathrm{H}$ and ${ }^{13} \mathrm{C}$ signals, starting from the known to unknown signals.

\section{Introduction}

NMR spectrometry is a technique widely used by scientists for structural elucidation and identification of chemical species [1-3], and to gain information about types, numbers and connectivity of particular atoms to deduce structures of organic, inorganic and biological molecules [4-5].

The principle of NMR spectroscopy is based on the magnetic properties of some nuclei [6]. Depending upon the atomic number and mass number of a nucleus, there is an associated angular momentum spin number. For a particular spin number, an isotopic nucleus may give rise to a magnetic field that can absorb energy from a pulsed radio frequency in a strong magnetic field and subsequently the energy can be released when the radio frequency is removed [7]. The release of energy will simultaneously give a weak signal, which represents the structural information about the individual nucleus and its surroundings. The released signal is detected, analyzed, and expressed as chemical shift (measured in ppm) and spin coupling. The most useful nuclei in carbohydrate research are ${ }^{1} \mathrm{H}$ and ${ }^{13} \mathrm{C}[8] .{ }^{1} \mathrm{H}$ NMR signals are much more sensitive than ${ }^{13} \mathrm{C}$ signals due to their natural abundance. Therefore, using one dimensional proton NMR alone to solve a structural problem of complex organic molecules is very difficult [9-11].

The most recent development in two and multi-dimensional NMR techniques has significantly improved the resolution and sensitivity of NMR spectroscopy. For example, homonuclear correlated spectra are extremely useful for assigning $1 \mathrm{H}$ resonances while the complete assignment of ${ }^{13} \mathrm{C}$-resonances is achieved by ${ }^{1} \mathrm{H}-{ }^{13} \mathrm{C}$ heteronuclear correlation [6, 12-14].

Product of reactions unless properly characterized, amounts to uncertainty and lack of control over the structures. To deduce the structure of a compound, there is the need to measure, analyse and interpret spectral data. However, spectral is not always simple and straight forward, thus the chemist would need a range of available techniques for analysis and interpretation such spectra [9].

$$
\text { ( } \beta \text {-glucose }) \quad(\alpha \text {-glucose })
$$

Step by step analysis of D-(+)-glucose was provided by processing and interpreting the measured data of the sample using spinworks. Fourier transformed 1-Dimensional NMR was combined with Fourier transformed 2-Dimensional NMR spectrometry for the interpretation of the spectral, because ${ }^{2} \mathrm{D}$ has the advantage of having more accurate assignments. 


\section{Materials And Methods}

2.1 Sampling and sample preparation

D-glucose $\left(98 \%{ }^{13} \mathrm{C}_{6}\right)$ with molecular formula $\mathrm{C}_{6} \mathrm{H}_{12} \mathrm{O}_{6}$ and molecular weight of 180.16 Daltons used was obtained from sigma and Aldrich. D-glucose $(89 \mathrm{mg})$ was dissolved in deuterated dimethyl sulfoxide $\left(\mathrm{D}_{6^{-}}\right.$ DMSO, $0.7 \mathrm{ml}$ ), and $5 \mathrm{ml}$ pipetted into a clean and dried NMR tube, which was then sealed with paraffin, ready for spectral analysis. The sample spectral of $1 \mathrm{D}{ }^{1} \mathrm{H}-\mathrm{NMR}$ without water suppression, $1 \mathrm{D}$ carbon $1 \mathrm{D}{ }^{13} \mathrm{C}-$ DEPT135, 2D COSY, 2D HSQC, 2D TOCSY, 2D HMQC, and 2D HMBC techniques were determined at $400 \mathrm{MHZ}$, in Manchester Interdisciplinary Biocentre using Bunker NMR, and spectral analysed using spinworks

\section{Results And Discussion}

The results obtained from the spectral data were systematically combined to elucidate the structure of the D- glucose. The analysis of the individual spectrum shows that the structure of D-glucose cannot be deduced completely from just one spectrum. Where a portion of an interpretation proved difficult, the next appropriate spectral that will make the interpretation easier was considered.

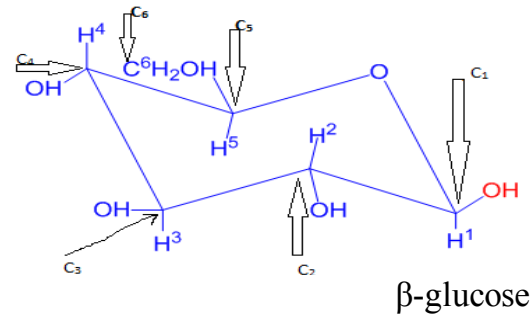

The six carbons in $\beta$-glucose are labelled from $C_{1}$ to $C_{6}$ in anticlockwise direction and each of the hydrogen attached to them were also labelled as $\mathrm{H}_{1}$ to $\mathrm{H}_{6}$ respectively.

\section{$3.1 \quad{ }^{1}$ H-NMR technique}

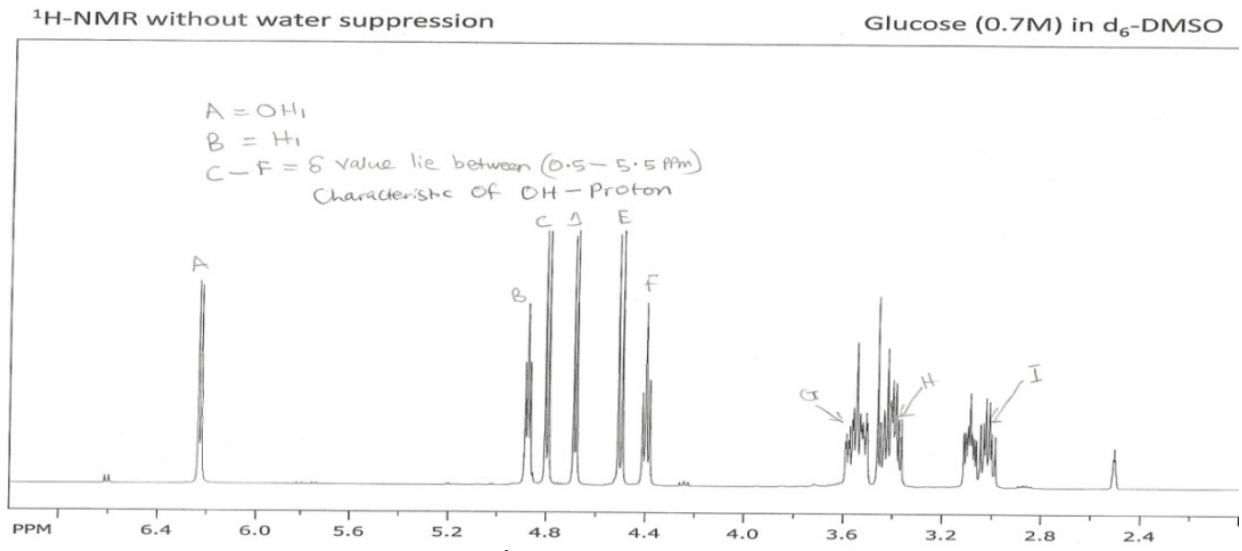

Figure 1 Spectrum of $1 \mathrm{D}^{1} \mathrm{H}$ NMR (peaks labelled from A to I)

Table1 Analysis of the $1 \mathrm{D}^{1} \mathrm{H}$ NMR spectral

\begin{tabular}{|l|l|l|l|l|}
\hline Proton & $\delta$ & Multiplicity & J in Hz & Integral \\
\hline $\mathrm{OH}_{1}$ & 6.2344 & d & 4.6870 & 1.0000 \\
\hline $\mathrm{H}_{1}$ & 4.8947 & t & 4.2550 & 1.0892 \\
\hline $\mathrm{OH}_{4}$ & 4.8156 & d & 5.5500 & 1.0046 \\
\hline $\mathrm{OH}_{3}$ & 4.7014 & d & 4.9950 & 1.0052 \\
\hline $\mathrm{OH}_{2}$ & 4.5197 & d & 6.4750 & 1.0455 \\
\hline $\mathrm{OH}_{6}$ & 4.4138 & $\mathrm{t}$ & 5.9200 & 1.0192 \\
\hline
\end{tabular}

From figure 1, integration of $\mathrm{A}=1.0000, \mathrm{~B}-\mathrm{F}=5.2169, \mathrm{G}-\mathrm{H}=4.4190, \mathrm{I}=2.0900$, Ratio of 1:5:4:2 from left to right, G-I shows multiplicity that was not clear in this spectrum. Total number of proton environment to be accounted is 12. From figure 1,12 protons were detected. Using spinworks, peaks appeared as either a doublet (A, C, D and E) or as a triplet (A and F). Peaks G to I showed multiplicity, thus not clear; a problem which could only be solved using a 2D shift correlated NMR spectroscopy. 
A doublet appears at $6.2338 \delta$ (peak A) which was in consistence with the presence of a proton that is bonded to a carbon $\left(\mathrm{C}_{1}\right)$ that is bonded to two oxygen atoms. Peak A was identified as $\mathrm{OH}_{1}$ and peak $\mathrm{B}$ as $\mathrm{H}_{1}$, since $\mathrm{OH}_{1}$ will be most deshielded followed by $\mathrm{H}_{1}$ attached to the same carbon $\left(\mathrm{C}_{1}\right)$. Peaks $\mathrm{C}$ to $\mathrm{F}$ were characteristic of $\mathrm{OH}$ protons $(0.5-5.5 \mathrm{ppm})$. The ${ }^{3} \mathrm{JH}, \mathrm{H}$ coupling constant values in Table 1 falls within the theoretical value $(0-18 \mathrm{~Hz})$ (Akit, 1992$)$. Integration shows that there were 12 proton environments.

\section{$3.21 \mathrm{D}{ }^{13} \mathrm{C}$ NMR technique}

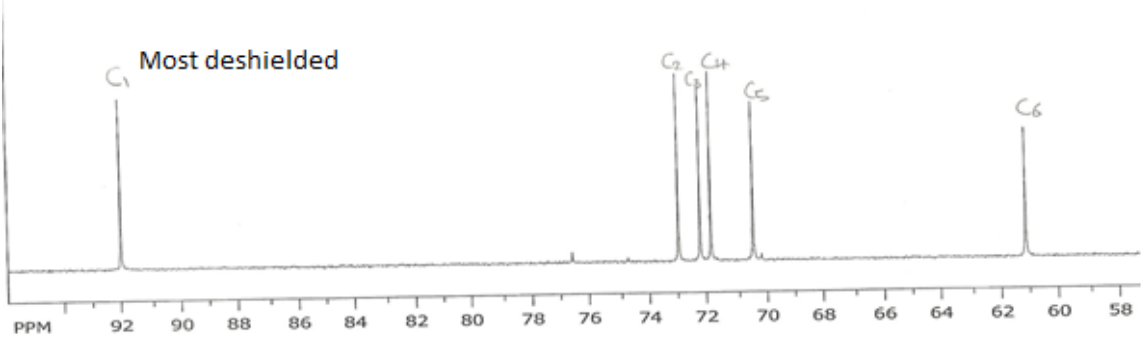

Figure 2 Spectrum of $1 \mathrm{D}^{13} \mathrm{C}$ NMR

Table 2 Analysis of the $1 \mathrm{D}{ }^{13} \mathrm{C}$ NMR spectral

\begin{tabular}{|l|l|}
\hline Carbon & Chemical shift( $($ ) \\
\hline $\mathrm{C}_{1}$ & 92.1375 \\
\hline $\mathrm{C}_{2}$ & 72.9877 \\
\hline $\mathrm{C}_{3}$ & 72.2516 \\
\hline $\mathrm{C}_{4}$ & 71.8865 \\
\hline $\mathrm{C}_{5}$ & 70.4292 \\
\hline $\mathrm{C}_{6}$ & 61.0899 \\
\hline
\end{tabular}

There are 6 carbon environments and all were visible, indicating that there was no symmetry. The Carbon that appears at 92.1375 ppm (table2) is $C_{1}$ because the most deshielded carbon will be the carbon that is attached to two oxygen atoms.

$3.3{ }^{13} \mathrm{C}$ DEPT-135 technique

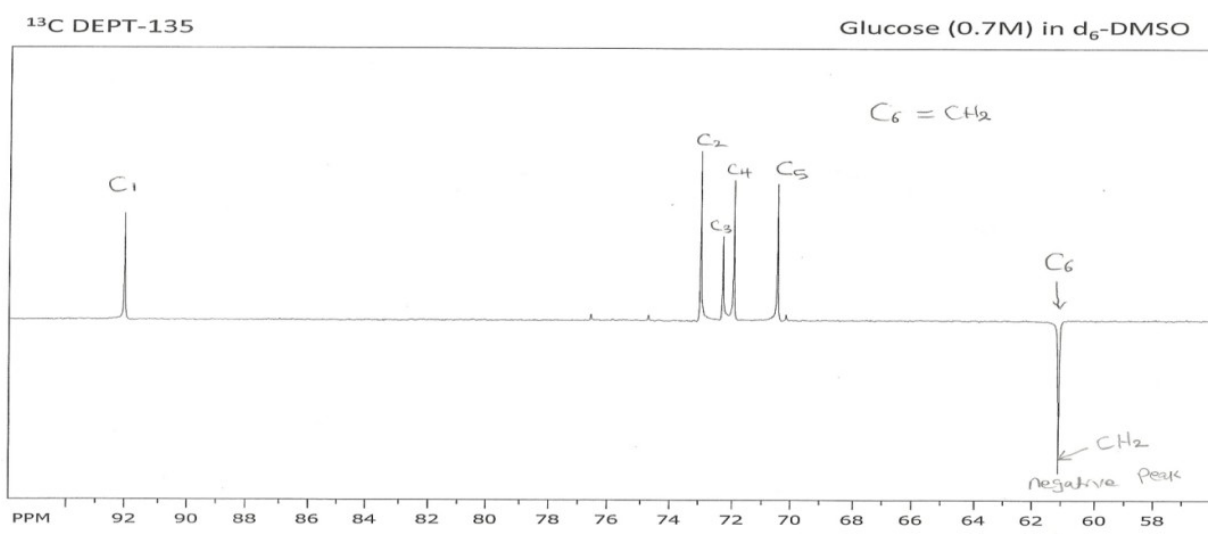

Figure $3{ }^{13} \mathrm{C}$ DEPT-135 Showing $\mathrm{CH}_{2}$ inverted and $\mathrm{CH}$ and $\mathrm{CH}_{3}$ not inverted

The only inverted peak at $61.0899 \mathrm{ppm}$ was $\mathrm{CH}_{2}$ (even number of $\mathrm{H}$ ) and so identified as $\mathrm{C}^{6}$. The remaining peaks were either for $\mathrm{CH}_{3}$ or $\mathrm{CH}$ (odd number of $\mathrm{H}$ ), but there was no $\mathrm{CH}_{3}$ in the compound; hence the peaks might be for $\mathrm{CH}$. 


\subsection{D HSQC (Heteronuclear Single Quantum Correlation)}

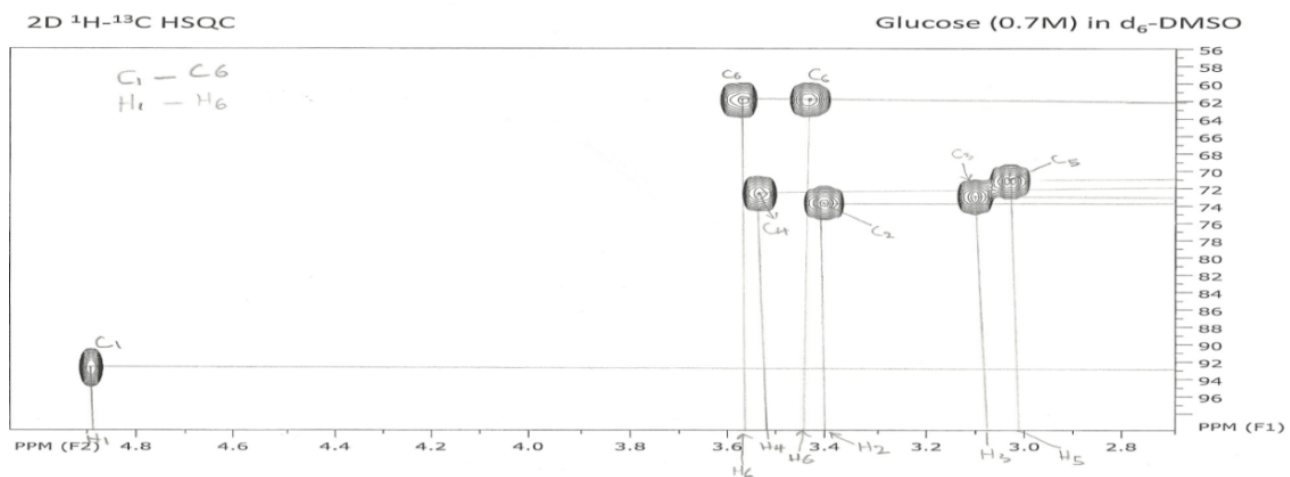

Figure 4 2D HSQC $\left({ }^{1} \mathrm{H}-{ }^{13} \mathrm{C}\right)$ Direct Proton - Carbon Correlation

Table 4 Analysis of 2D HSQC $\left({ }^{1} \mathrm{H}^{-13} \mathrm{C}\right)$ spectral

\begin{tabular}{|lll|l|}
\hline $\mathrm{C}_{1} 92.9158$ Correlate with & $\mathrm{H}_{1} 4.9007$ \\
\hline $\mathrm{C}_{2} 72.9748$ " & & $\mathrm{H}_{2} 3.4040$ \\
\hline $\mathrm{C}_{3} 72.3613$ " & & $\mathrm{H}_{3} 3.0956$ \\
\hline $\mathrm{C}_{4} 71.9151$ & & & $\mathrm{H}_{4} 3.5371$ \\
\hline $\mathrm{C}_{5} 70.5208$ & " & & $\mathrm{H}_{5} 3.0276$ \\
\hline $\mathrm{C}_{6} 61.0397$ & & $\mathrm{H}_{6} 3.5696,3.4335$ \\
\hline
\end{tabular}

From Table $4, \mathrm{C}_{1}$ to $\mathrm{C}_{6}$ are directly bonded to $\mathrm{H}_{1}$ to $\mathrm{H}_{6}$ respectively using their chemical shift values.

\subsection{D Cosy}

COSY is a ${ }^{1} \mathrm{H}$ homonuclear shift correlation spectrum which contains information on spin coupling networks within a constituent residue through the observation of cross peaks off the diagonal [14]. The strategy of assigning a COSY spectrum is to find one unmistakably characteristic signal from which to begin the tracing of a spin system or network. An anomeric proton is often chosen as the starting point because it is connected to a carbon bearing two oxygen atoms, which is probably the most down field [2]. ${ }^{1} \mathrm{H}$ signal correlation Spectroscopy $\left({ }^{1} \mathrm{H}-{ }^{1} \mathrm{H}\right.$ Correlation) correlates proton that are three bonds away .

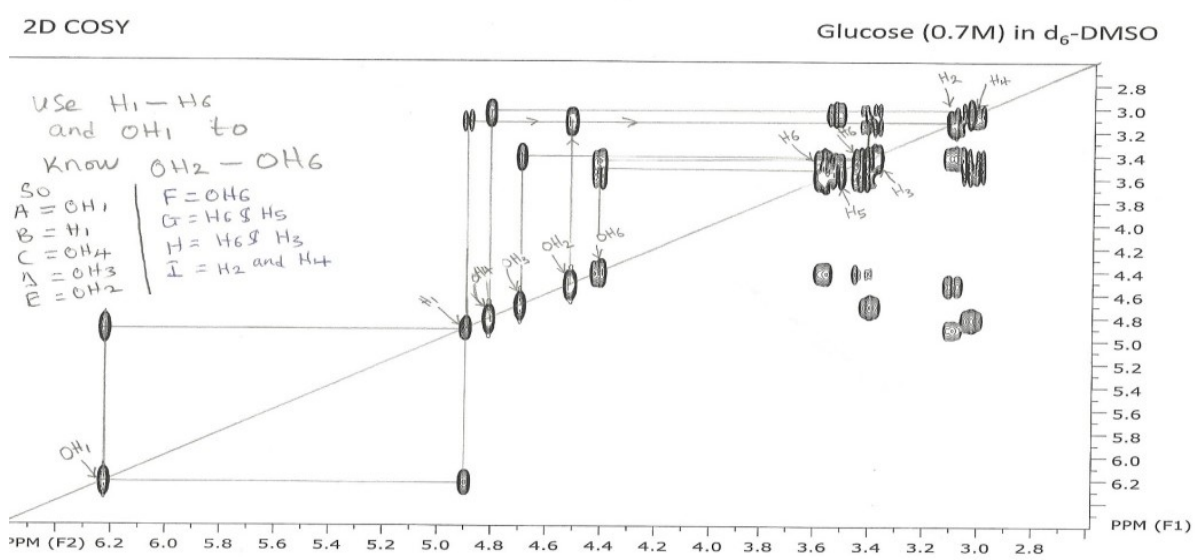

Figure $52 \mathrm{D}$ Cosy ${ }^{1} \mathrm{H}-{ }^{1} \mathrm{H}$ correlation -3 bonds away

Table 5 Analysis of the 2D Cosy - 3 bonds away

\begin{tabular}{|l|l|l|l|}
\hline Proton & Correlate with & Proton & Correlate with \\
\hline $\mathrm{OH}_{1}$ & $\mathrm{H}_{1}$ & $\mathrm{H}_{1}$ & $\mathrm{H}_{2}$ \\
\hline $\mathrm{OH}_{2}$ & $\mathrm{H}_{2}$ & $\mathrm{H}_{2}$ & $\mathrm{H}_{3}$ \\
\hline $\mathrm{OH}_{3}$ & $\mathrm{H}_{3}$ & $\mathrm{H}_{3}$ & $\mathrm{H}_{4}$ \\
\hline $\mathrm{OH}_{4}$ & $\mathrm{H}_{4}$ & $\mathrm{H}_{4}$ & $\mathrm{H}_{5}$ \\
\hline $\mathrm{OH}_{6}$ & $\mathrm{H}_{6}$ & $\mathrm{H}_{5}$ & $\mathrm{H}_{6} * 2$ \\
\hline
\end{tabular}


Correlation results between protons that are coupled to each other (form squares from diagonal and cross peaks) are presented in Table 5. This is particularly useful because of the complicated signals in peaks from $\mathrm{G}$ to I. From figure 5, the diagonal and cross peaks formed by joining solid lines shows which protons are coupled to each other (mutual scalar coupling). $\mathrm{OH}_{1}$ to $\mathrm{OH}_{4}$ correlates with $\mathrm{H}_{1}$ to $\mathrm{H}_{4}$ respectively and $\mathrm{OH}_{6}$ correlates with $\mathrm{H}_{6}$. Also, $\mathrm{H}_{1}$ to $\mathrm{H}_{5}$ correlates $\mathrm{H}_{2}$ to $\mathrm{H}_{6}$ respectively but $\mathrm{H}_{5}$ correlates with two $\mathrm{H}_{6}$ at $3.5604 \mathrm{ppm}$ and $3.4171 \mathrm{ppm}$.

\subsection{D ${ }^{1} \mathrm{H}-{ }^{13} \mathrm{C}$ HMBC}

The HMBC experiment detects long range coupling between proton and carbon (two or three bonds away) with great sensitivity. This technique is very valuable for detecting indirectly quaternary carbons coupled to protons and is especially useful if direct carbon-13 is impossible to obtain due to a low amount of material available [12].This very useful sequence provides information about the skeleton of a molecule. In HMBC, carbon correlates with hydrogen 2-4 bonds away [13].

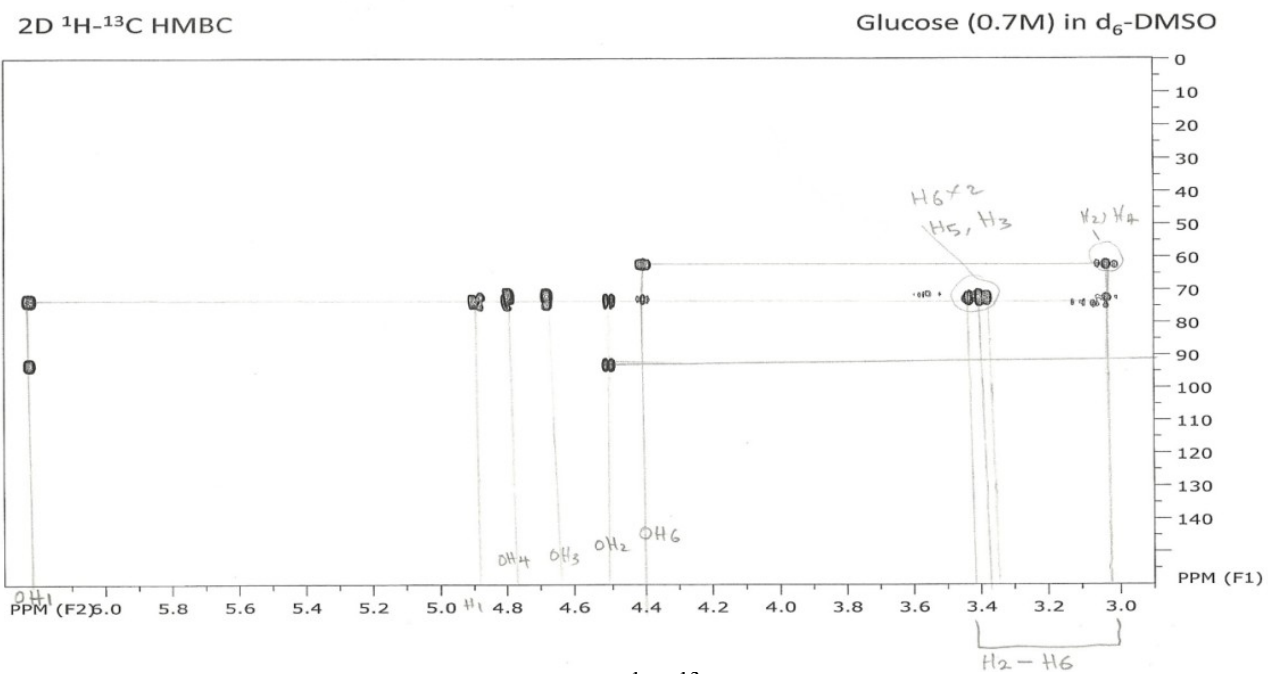

Figure 6: Spectrum of 2D HMBC $\left({ }^{1} \mathrm{H}-{ }^{13} \mathrm{C}\right)$ correlation 2-4 bonds away

Table 6: 2D HMBC $\left({ }^{1} \mathrm{H}^{-13} \mathrm{C}\right)$ Correlation 2-4 Bonds away

\begin{tabular}{|l|l|l|l|l|l|l|l|l|l|l|l|}
\hline Carbon & $\mathrm{H}_{1}$ & $\mathrm{H}_{2}$ & $\mathrm{H}_{3}$ & $\mathrm{H}_{4}$ & $\mathrm{H}_{5}$ & $\mathrm{H}_{6}$ & $\mathrm{OH}_{1}$ & $\mathrm{OH}_{2}$ & $\mathrm{OH}_{3}$ & $\mathrm{OH}_{4}$ & $\mathrm{OH}_{6}$ \\
\hline $\mathrm{C}_{1}$ & & & & & & & $*$ & $*$ & & & \\
\hline $\mathrm{C}_{2}$ & $*$ & & & & & & $*$ & $*$ & $*$ & $*$ & \\
\hline $\mathrm{C}_{3}$ & $*$ & & & & & & & $*$ & $*$ & & \\
\hline $\mathrm{C}_{4}$ & $*$ & $*$ & & & & $*$ & & $*$ & $*$ & $*$ & $*$ \\
\hline $\mathrm{C}_{5}$ & & & & $*$ & & $*$ & & & $*$ & $*$ & \\
\hline $\mathrm{C}_{6}$ & & & $*$ & & $*$ & & & & & & $*$ \\
\hline
\end{tabular}

From Table 5, the cells marked with * signifies correlation. The appearance of at least a $*$ in a column shows that there was a correlation between all nuclides of interest (carbon and hydrogen), $\mathrm{C}_{1}$ to $\mathrm{C}_{6}$ with $\mathrm{OH}_{1}$, $\mathrm{OH}_{2}, \mathrm{OH}_{3}, \mathrm{OH}_{4}$ and $\mathrm{OH}_{6}$, and $\mathrm{H}_{1}$ to $\mathrm{H}_{6}\left(\right.$ two $\left.\mathrm{H}_{6}\right)$. The results in Table 5 also indicated that a carbon sees at least a proton and vice versa.

\subsection{D TOCSY}

Total correlated spectroscopy (TOCSY), also known as homonuclear Hartmann-Hahn spectroscopy (HOHAHA), correlates protons that are in the same spin system and yields both long range and short range correlations. It is useful for establishing the scalar connectivity if the proton signals are from within a spin system, especially when the multiplets overlap or there is extensive second order coupling [14-15]. All protons of a coupled system are known from here. All the protons are coupled to each other as shown in figure 6 


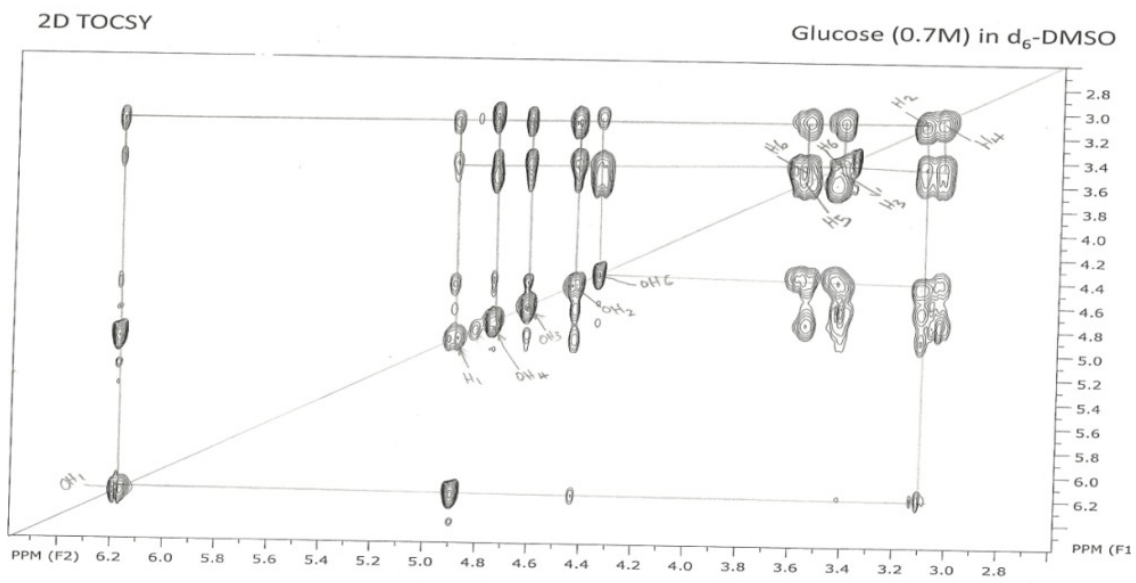

Figure $7{ }^{1} \mathrm{H}-{ }^{1} \mathrm{H}$ Correlation -5 bonds away

\section{$3.8^{2} \mathrm{D}^{1} \mathrm{H}-{ }^{13} \mathrm{C}$ HSQC-TOCSY}

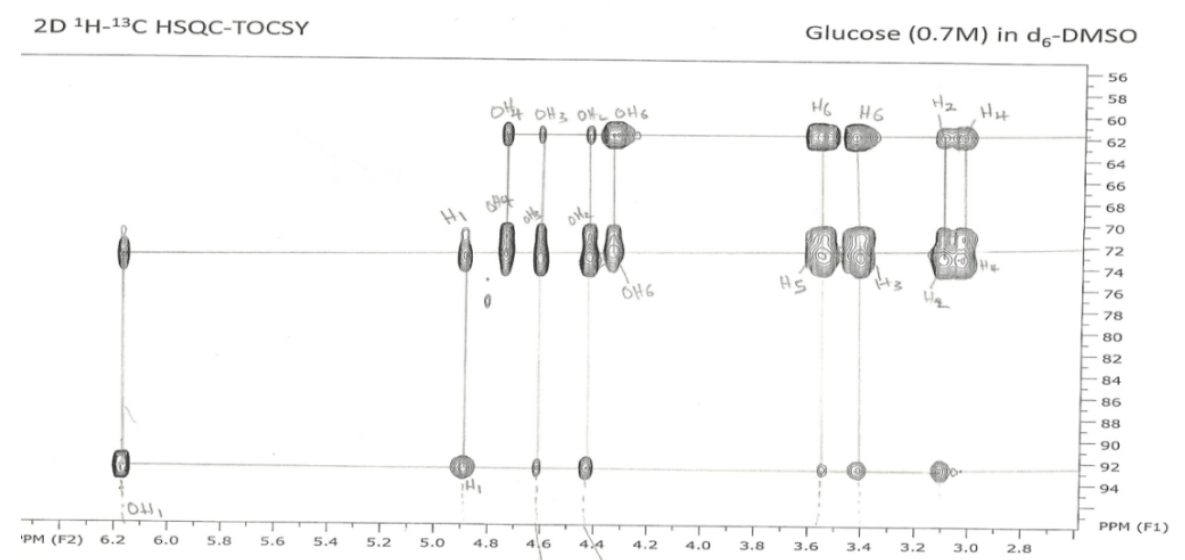

Figure $82 \mathrm{D}^{1} \mathrm{H}^{-13} \mathrm{C}$ HSQC-TOCSY Showing coupling between all hydrogen and Carbon atoms

All coupled nuclides become strongly coupled due to complete correlation between all the carbons with the hydrogen atoms. This was used to confirm the coupling of all the coupled spin system to elucidate the full structure

\section{Conclusion}

NMR spectroscopy has been demonstrated to be the most powerful tool in structural analysis. Structural elucidation is systematic and coherent. A COSY experiment will overcome most of the overlap problems in the 1D spectrum with the assistance of TOCSY NMR. Full characterization of D- glucose was done by assigning ${ }^{1} \mathrm{H}$ and ${ }^{13} \mathrm{C}$ signals, starting from known to unknown signals.

\section{Acknowledgement}

Dr Vasudevan Ramesh of the School of Chemistry, Manchester Interdisciplinary Biocentre, University of Manchester, is appreciated for running the spectral data of the D-glucose.

\section{References}

[1] J. W. Akitt, An introduction to modern spectroscopy, (Chapman and Hall, London, 1992).

[2] H. Frieboline, Basic one and two-dimensional NMR Spectroscopy, (Wiley-VCH, Germany, 2004).

[3] W. A. Bubb, NMR Spectroscopy in the Study of Carbohydrates: Characterizing the structural complexity and concepts, Magnetic Resonance Part A, 19A (1), 2003, 1-19.

[6] I. P. Gerothanassis, A. Troganis, V. Exarchou, K. Barbarossou, Nuclear Magnetic Resonance (NMR) spectroscopy: Basic principles and phenomena, and their applications to Chemistry, Biology and Medicine. Chemistry Education, Research and Practice in Europe, 3(2), 2002, 229-252

[7] H. Ikeda, , N. Yuichi, D. Yi-qun, I. Tsukasa, F. Toda, Modifications of the secondary hydroxyl side of $\alpha$-cyclodextrin and NMR studies of them, Tetrahedron Letters 31(35), 1990, 5045-5048.

[8] E. Sawen, NMR spectroscopy and MD simulations of carbohydrates, (Sweden, US-AB, Stockholm, 2011). 
[9] B.R. Leeflang, E.J. Faber, P. Erbel, J.F.G. Vliegenthart, Structure elucidation of glycoprotein glycans and of polysaccharides by NMR spectroscopy, Journal of Biotechnology 77, 2000, 115-122

[10] J. Duus, C. H Gotfredsen, K. Bock, Carbohydrate structural determination by NMR spectroscopy: modern methods and limitations, Chemical Revelation, 100, 2000, 4589-4614.

[11] W. C. Steve, Structural Analysis of Polysaccharides (Taylor \& Francis Group, LLC, 2005)

[12] A. Ono, T. Shin-ichi, I. Yoshiharu, K. Masatsune, Preparation and Heteronuclear 2D NMR Spectroscopy of a DNA Dodecamer containing a thymidine residue with a uniformly ${ }^{13} \mathrm{C}$-labeled deoxyribose ring, Journal of Biomolecular NMR, 4(4), 1994, 581-86.

[13] H.Watanabe, M. Umeda, Y. Ishihara, K. Okamoto, K. Oshio, T. Kanamatsu, Y. Tsukada, Human brain glucose metabolism mapping using multislice $2 \mathrm{D}^{1} \mathrm{H}^{13} \mathrm{C}$ Correlation HSQC Spectroscopy, Magnetic Resonance in Medicine 43(4), 2000, 525-533.

[14] S.Massou, N.Cécile, L. Fabien, P. Jean-Charles, Application of 2D-TOCSY NMR to the measurement of specific complexes and metabolites, Metabolic Engineering, 9 (3), 2007, 252-57.

[15] M. J. Pregel, B. Erwin, Cyclodextrin-Based Enzyme Models. Part 1. Synthesis of a tosylate and an epoxide derived from heptakis (6-O-Tert-Butyldimethylsilyl)-B-Cyclodextrin and their characterization Using 2D NMR techniques. An improved route to cyclodextrins functionalized on the secondary face, Canadian Journal of Chemistry, 69(1), 1991, 130-37. 